\title{
Low hepatic iron concentration: evaluation of two complementary methods, colorimetric assay and iron histological scoring
}

Françoise Imbert-Bismut, Frederic Charlotte, Bruno Turlin, Lina Khalil, Annie Piton, Pierre Brissot, Yves Le Charpentier, Jacques Delattre, Pierre Opolon, Yves Deugnier, Thierry Poynard

Laboratoire de Biochimie, Hôpital Pitié-Salpêtrière 75013

Paris, France

F Imbert-Bismut

L Khalil

A Piton

J Delattre

Laboratoire

d'Anatomie

Pathologique, Hôpital

Pitié-Salpêtrière

F Charlotte

Y Le Charpentier

Laboratoire atogastroentérologie,ised human liver biopsies. In secondary Hôpital Pitié-Salpêtrière P Opolon

T Poynard

Laboratoire

d'Anatomie

Pathologique B, U-49

de l'INSERM, CHRU

Pontchaillou 35033

Rennes, France

B Turlin

Clinique des Maladies du Foie and Unités de Recherches

Hépatologiques, U-49 de l'INSERM

P Brissot

Y Deugnier

Correspondence to: Dr Imbert-Bismut.

Accepted for publication 18 February 1999

Keywords: iron; liver; chemical liver iron assessment; histological liver iron assessment

Recent studies have emphasised the pathophysiological role of iron in various liver diseases with low iron excess, such as viral chronic hepatitis C. ${ }^{1}$ Experimental investigations have suggested that iron may play a role in liver fibrogenesis as a cofactor in lipid peroxidation. $^{23}$ Some clinical studies have shown that the hepatic iron content may influence the response to interferon alfa treatment in chronic hepatitis $\mathrm{C}^{4-7}$ while others have not. ${ }^{8-10}$ This discrepancy could partly be \begin{abstract}
ing low iron concentrations in deparaffin-
Abstract

Aims-To validate a method of assessment of low hepatic iron concentration based on a biochemical colorimetric assay plus histological scoring.

Methods-The within-day and day to day precision of the iron colorimetric assay was determined on frozen rat liver. The coefficient of variation (CV) of iron measurement in two separate samples from the same liver was determined for 21 deparaffinised human biopsies. The intraand interlaboratory variability of the colorimetric assay and histological scoring were assessed on 38 deparaffinised liver biopsies.

Results-For the within-day test, the CV was $11 \%(5.1(0.6) \mu \mathrm{mol} / \mathrm{g}$ dry weight (dw), mean (SD) iron concentration). For the day to day test, the CV was $19.5 \%$ (8.2 (1.6) $\mu \mathrm{mol} / \mathrm{g} \mathrm{dw})$. The CV was $14.7 \%$ for iron concentration determined in two separate samples from the same liver. By correlation and $\kappa$ concordance tests, the intraand interlaboratory variability of the hepatic iron colorimetric assay and iron histological scoring was slight. Absence of stainable iron corresponded to a liver iron concentration $\leqslant 20 \mu \mathrm{mol} / \mathrm{g} \mathrm{dw}$.

Conclusions-A combination of two complementary methods, colorimetric measurement and histological scoring, is an accurate and reliable way of determinhaemosiderosis, such methods would be essential for investigating the role of low iron overload in fibrogenesis and during the response to antiviral treatment in chronic viral hepatitis.

(F Clin Pathol 1999;52:430-434)
\end{abstract}

explained by the difference in the sensitivity of assessment methods for the low liver iron content usually found in patients with hepatitis C. ${ }^{411} \mathrm{~A}$ high liver iron content can be evaluated by two direct methods: colorimetric measurement of iron concentration and histological scoring of stainable iron. ${ }^{12}{ }^{13}$ The quantitative chemical method assesses all liver iron forms, whereas the semiquantitative histological analysis evaluates only the haemosiderin iron form and not the unstainable ferritin iron form. ${ }^{14}{ }^{15}$ The aim of this study was therefore to validate these two methods for low iron levels by (1) determining the accuracy of the colorimetric measurement of hepatic iron concentration, (2) estimating the intralaboratory and interlaboratory variability in colorimetric assessment and histological scoring, and (3) evaluating histological iron scoring using the colorimetric iron assay

\section{Methods}

LIVER SAMPLE SELECTION

A frozen Wistar rat liver was used for the study of reliability criteria for determining iron concentration. The variability of the iron concentration measurement and histological scoring was evaluated in $4 \%$ formalin fixed, paraffin embedded human hepatic biopsies that were large enough for several chemical iron determinations. These liver specimens were obtained by percutaneous needle or wedge biopsies in 13 and 25 cases, respectively. Clinical data and the results of hepatic iron concentration measurements and histological scores are listed in table 1 . There were 38 patients (median age 49 years): 18 men (median age 56 years, range 28 to 74 ) and 20 women (median age 48 years, range 19 to 72 ).

IRON HISTOLOGICAL SCORING

Liver sections $(3 \mu \mathrm{m})$ were stained using Perls' reaction. We followed the quantitative histological grading previously used and modified by Deugnier et al. ${ }^{16}$ The total iron score (0-60) was equal to the sum of hepatocytic, sinusoidal, and portal scores multiplied by a heterogeneity coefficient defined according to iron distribution as follows: $1 / 3$, very heterogeneous; $2 / 3$, moderately heterogeneous; $3 / 3$, homogeneous. To evaluate interobserver variation, the same set of slides was independently reviewed by two pathologists (FC and BT) without previous knowledge of the corresponding biochemical results. For intraobserver variation, each 
pathologist re-examined the slides after a three month interval.

DETERMINATION OF HEPATIC IRON

CONCENTRATION

Paraffin embedded specimens were deparaffinised initially by melting the paraffin at $60^{\circ} \mathrm{C}$ until the samples were released from the block, followed by three successive immersions of 30 minutes each in xylene and then in ethanol. Next, specimens were oven dried for 24 hours and weighed on a microbalance with $0.01 \mathrm{mg}$ precision. The mean (SD) dry weight (dw) of liver specimens was $1.18(0.36) \mathrm{mg}$ (range 0.60 to $1.76 \mathrm{mg}$ ). Hepatic iron concentration was measured using the colorimetric method described by Barry and Sherlock. ${ }^{17}$ Chemical assay and histological scoring had to be performed on a representative liver sample, the dry weight and the length of which had to be $\geqslant 0.50 \mathrm{mg}$ and $\geqslant 5 \mathrm{~mm}$, respectively. In each assay, it was essential that the absorbance of the blank assay was $<0.0060$ to verify that reagents and washed glassware were uncontaminated by iron. The absorbance reading was performed by a Beckman DU 640 spectrophotometer. A linear calibration was obtained for an iron concentration range of 0 to $14.9 \mu \mathrm{mol} /$ litre. Under these conditions, the analytical sensitivity of the method was about 0.3 $\mu \mathrm{mol} /$ litre. Iron concentration was determined in two different samples from the same liver biopsy and each sample was assayed in duplicate. Results are expressed as $\mu \mathrm{mol} / \mathrm{g} d w$

Table 1 Clinical, biochemical, and histological data on 38 patients

\begin{tabular}{|c|c|c|c|c|c|}
\hline Patient & Clinical condition & $\operatorname{Sex}$ & $\begin{array}{l}\text { Age } \\
\text { (years) }\end{array}$ & $\begin{array}{l}\text { Hepatic iron } \\
\text { ( } \mu \text { mol/g dw) }\end{array}$ & $\begin{array}{l}\text { Histological } \\
\text { grade }\end{array}$ \\
\hline 1 & Viral hepatitis C & $\mathrm{F}$ & 40 & 3 & 0 \\
\hline 2 & Viral hepatitis $\mathrm{C}$ & $M$ & 47 & 3 & 0 \\
\hline 3 & Viral hepatitis C & $\mathrm{F}$ & 62 & 4 & 0 \\
\hline 4 & Viral hepatitis C & $M$ & 56 & 4 & 0 \\
\hline $5^{\star}$ & Viral hepatitis C & M & 29 & 4 & $1(1 / 3)$ \\
\hline 6 & Viral hepatitis C & $\mathrm{F}$ & 47 & 5 & 0 \\
\hline 7 & Viral hepatitis C & $\mathrm{F}$ & 48 & 5 & 0 \\
\hline 8 & Viral hepatitis C & $M$ & 32 & 6 & 0 \\
\hline 9 & Viral hepatitis C & $\mathrm{F}$ & 62 & 7 & 0 \\
\hline 10 & Viral hepatitis C & M & 28 & 8 & 3 \\
\hline 11 & Viral hepatitis C & $\mathrm{F}$ & 58 & 9 & 0 \\
\hline 12 & Viral hepatitis C & $M$ & 74 & 11 & 1 \\
\hline $13^{\star}$ & Viral hepatitis C & $M$ & 69 & 16 & $2(2 / 3)$ \\
\hline 14 & Viral hepatitis C & $\mathrm{F}$ & 72 & 22 & 3 \\
\hline 15 & Viral hepatitis C & $\mathrm{F}$ & 49 & 48 & 25 \\
\hline 16 & Viral hepatitis $B+C$ & $\mathrm{~F}$ & 60 & 14 & 0 \\
\hline 17 & Viral hepatitis B & M & 73 & 8 & 0 \\
\hline $18^{\star}$ & Steatosis & $M$ & 57 & 16 & $2(1 / 3)$ \\
\hline 19 & Steatosis & $M$ & 71 & 70 & 9 \\
\hline 20 & Alcoholic hepatitis & $\mathrm{F}$ & 45 & 7 & 0 \\
\hline 21 & Secondary haemosiderosis & $\mathrm{F}$ & 29 & 204 & 15 \\
\hline 22 & Secondary haemosiderosis & M & 36 & 365 & 24 \\
\hline 23 & Liver trauma & $\mathrm{F}$ & 65 & 7 & 0 \\
\hline 24 & Liver trauma & $\mathrm{F}$ & 19 & 8 & 0 \\
\hline 25 & Liver trauma & $\mathrm{F}$ & 32 & 8 & 0 \\
\hline 26 & Liver trauma & M & 29 & 9 & 0 \\
\hline 27 & Liver trauma & $\mathrm{F}$ & 30 & 9 & 0 \\
\hline 28 & Liver trauma & M & 47 & 11 & 0 \\
\hline 29 & Liver trauma & M & 35 & 16 & 0 \\
\hline 30 & Vesicular lithiasis & M & 69 & 26 & 4 \\
\hline 31 & Haemolytic anaemia & $\mathrm{F}$ & 21 & 61 & 6 \\
\hline 32 & Liver congestion & $\mathrm{F}$ & 27 & 3 & 0 \\
\hline 33 & Liver congestion & $\mathrm{F}$ & 52 & 4 & 0 \\
\hline 34 & Amyloidosis & $\mathrm{F}$ & 49 & 16 & 0 \\
\hline $35^{\star}$ & Hepatocellular carcinoma & M & 71 & 12 & $1(1 / 3)$ \\
\hline 36 & Nodal lymphoma & M & 68 & 44 & 6 \\
\hline 37 & $\begin{array}{l}\text { Metastases (neuroendocrine } \\
\text { carcinoma) }\end{array}$ & $\mathrm{F}$ & 65 & 20 & 3 \\
\hline $38^{\star}$ & Metastases (adenocarcinoma) & M & 56 & 33 & $12(2 / 3)$ \\
\hline
\end{tabular}

${ }^{\star}$ Patients 5, 13, 18, 35, and 38: iron heterogeneously distributed (heterogeneity coefficient). dw, dry weight. of liver tissue. The chemical determination of liver iron was performed without reference to histological scoring.

RELIABILITY CRITERIA FOR THE COLORIMETRIC

MEASUREMENT OF HEPATIC IRON

CONCENTRATION

Day to day reproducibility of the assay was determined over five days by measuring the iron content of 22 samples from the same rat liver. Within-day precision was determined by repeated iron concentration measurement of 10 samples from the same rat liver.

VARIABILITY IN COLORIMETRIC MEASUREMENT OF HEPATIC IRON CONCENTRATION AND IN IRON HISTOLOGICAL SCORING

The distribution of stainable hepatic iron was heterogeneous in five liver biopsies and homogeneous or not present in the other 33. Two groups of biopsies were defined as follows: (A) with homogeneous iron distribution or without iron; (B) biopsies from group A plus five biopsies with heterogeneous iron distribution. Variability of iron concentration determination was evaluated in the same laboratory as follows: intraoperator variations (LK) for biopsies of groups A $(n=28)$ and $B(n=33)$, and interoperator variations (LK, FIB) for groups A $(n=33)$ and $B(n=38)$. Interlaboratory variations (LK, JYR and FIB, JYR) were assessed for group A $(n=19)$.

Intralaboratory, intraobserver (FC), and interobserver (FC, BT) variability of stainable iron scoring was evaluated for groups $A(n=33)$ and $B(n=38)$.

\section{STATISTICAL METHODS}

Intraoperator and interoperator variations for iron concentration measurement were estimated by Bland-Altman plots, ${ }^{18}$ by the difference between result means, and by the $\kappa$ concordance test. ${ }^{19}$ Intraobserver and interobserver variations in iron histological scoring were estimated by the $\kappa$ concordance test. ${ }^{19}$

\section{Results}

VARIABILITY IN IRON HISTOLOGICAL SCORING

Stainable iron was observed in 16 of 38 biopsies, with an iron histological scoring range between 1 and 25 (table 2). In four cases iron histological scoring was $\geqslant 10$. The strength of intraobserver (FC) agreement was substantial for all histological items. If the five liver biopsies with heterogeneous iron distribution were excluded, the degree of intraobserver (FC) concordance was almost perfect except for the sinusoidal iron score. The degree of interobserver (FC, BT) concordance was lower, the strength of agreement being moderate for the sinusoidal iron score and substantial for the hepatocytic and portal iron scores. If the livers with heterogeneous iron distribution were excluded, no significant modification to the degree of interobserver concordance was observed except in the case of the portal iron score, where the strength of agreement was almost perfect. 
Table 2 Intraobserver and interobserver variations in iron histological scoring

\begin{tabular}{|c|c|}
\hline Variable & $\kappa$ Test \\
\hline \multicolumn{2}{|c|}{ Hepatocyte iron score } \\
\hline \multicolumn{2}{|c|}{ Intraobserver variation $(\mathrm{FC})$} \\
\hline$A(n=33)$ & $0.87^{\star}$ \\
\hline $\mathrm{B}(\mathrm{n}=38)$ & $0.74^{\star}$ \\
\hline \multicolumn{2}{|c|}{ Interobserver variation $(\mathrm{FC}, \mathrm{BT})$} \\
\hline $\mathrm{A}(\mathrm{n}=33)$ & $0.62^{\star}$ \\
\hline $\mathrm{B}(\mathrm{n}=38)$ & $0.62^{\star}$ \\
\hline \multicolumn{2}{|c|}{ Sinusoidal iron score } \\
\hline \multicolumn{2}{|c|}{ Intraobserver variation $(\mathrm{FC})$} \\
\hline$A(n=33)$ & $0.73^{\star}$ \\
\hline $\mathrm{B}(\mathrm{n}=38)$ & $0.78^{\star}$ \\
\hline \multicolumn{2}{|c|}{ Interobserver variation $(\mathrm{FC}, \mathrm{BT})$} \\
\hline $\mathrm{A}(\mathrm{n}=33)$ & $0.52^{\star}$ \\
\hline $\mathrm{B}(\mathrm{n}=38)$ & $0.59^{\star}$ \\
\hline \multicolumn{2}{|c|}{ Portal iron score } \\
\hline \multicolumn{2}{|c|}{ Intraobserver variation $(\mathrm{FC})$} \\
\hline $\mathrm{A}(\mathrm{n}=33)$ & $0.82^{\star}$ \\
\hline $\mathrm{B}(\mathrm{n}=38)$ & $0.77^{\star}$ \\
\hline \multicolumn{2}{|c|}{ Interobserver variation $(\mathrm{FC}, \mathrm{BT})$} \\
\hline $\mathrm{A}(\mathrm{n}=33)$ & $0.84^{\star}$ \\
\hline $\mathrm{B}(\mathrm{n}=38)$ & $0.62^{\star}$ \\
\hline \multicolumn{2}{|c|}{ Iron histological score } \\
\hline \multicolumn{2}{|c|}{ Intraobserver variation (FC) } \\
\hline $\mathrm{A}(\mathrm{n}=33)$ & $0.82^{\star}$ \\
\hline $\mathrm{B}(\mathrm{n}=38)$ & $0.72^{\star}$ \\
\hline \multicolumn{2}{|c|}{ Interobserver variation $(\mathrm{FC}, \mathrm{BT})$} \\
\hline $\mathrm{A}(\mathrm{n}=33)$ & $0.65+$ \\
\hline $\mathrm{B}(\mathrm{n}=38)$ & $0.69 \dagger$ \\
\hline
\end{tabular}

A, biopsies not including the five biopsies with heterogeneous iron distribution; $\mathrm{B}$, biopsies with and without stainable iron; $\mathrm{FC}, \mathrm{BT}$, initials of investigators.

${ }^{{ }} \kappa$ for three classes of different iron histological score $(0 ; 0-5$; $>5$ ).

$\dagger \kappa$ for two classes of different iron histological score $(0 ;>0)$.

PRECISION OF COLORIMETRIC MEASUREMENT OF HEPATIC IRON CONCENTRATION

The within-day and day to day precision tests were satisfactory, since the coefficients of variation $(\mathrm{CV})$ were $11 \%$ (mean iron concentration $5.1(0.56) \mu \mathrm{mol} / \mathrm{g} \mathrm{dw}$ ) and $19.5 \%$ (mean $8.2(1.6) \mu \mathrm{mol} / \mathrm{g} \mathrm{dw}$ ), respectively. For 21 human biopsies in group A which were tested in duplicate (iron concentration $\leqslant 20 \mu \mathrm{mol} / \mathrm{g}$ $\mathrm{dw}$ ), the standard error for a single iron concentration determination corresponded to a CV of $14.7 \%$.

VARIABILITY IN CHEMICAL DETERMINATION OF HEPATIC IRON CONCENTRATION

These results are shown in table 3 and fig 1 . Median hepatic iron concentration was 9 $\mu \mathrm{mol} / \mathrm{g} \mathrm{dw}$ (range 3 to 365 ) for the 38 biopsies. Hepatic iron content was $\leqslant 20 \mu \mathrm{mol} / \mathrm{g} \mathrm{dw}$ in 28 biopsies, between 20 and $60 \mu \mathrm{mol} / \mathrm{g} \mathrm{dw}$ in seven, and $\geqslant 60 \mu \mathrm{mol} / \mathrm{g} \mathrm{dw}$ in three.

In the same laboratory, the intraoperator and interoperator variability of the iron colorimetric assay was slight. Between the two laboratories, using the same technique, the differences in the iron concentration results were minor. The $\kappa$ test showed an almost perfect strength of agreement for iron concentration classes 0 to 20,20 to 50 , and $>50 \mu \mathrm{mol} / \mathrm{g} \mathrm{dw}$ when determined by two operators in the same laboratory or in two different laboratories. The concordance of results was substantial for iron concentration classes 0 to 10,10 to 20,20 to 50 , and $>50 \mu \mathrm{mol} / \mathrm{g} \mathrm{dw}$ when iron concentrations were determined by the same operator in the same laboratory. The $\kappa$ tests for groups A and B were similar.
COMPARISON BETWEEN COLORIMETRIC DETERMINATION OF IRON CONCENTRATION AND HISTOLOGICAL SCORING

The clinical data and the results of iron concentration and histological scoring are summarised in table 1. Comparisons between iron concentration and histological scoring results are shown in fig 2 . For no stainable iron, the $\kappa$ test showed a substantial strength of agreement when the iron concentration was $\leqslant 15 \mu \mathrm{mol} / \mathrm{g} \mathrm{dw}(\kappa=0.74)$. It was almost perfect when the iron concentration was $\leqslant 20$ $\mu \mathrm{mol} / \mathrm{g} \mathrm{dw}(\kappa=0.86)$.

Table 3 Variability of determination of hepatic iron concentration

\begin{tabular}{|c|c|c|}
\hline Variable & $\Delta(S D)$ & $\kappa$ Test \\
\hline \multicolumn{3}{|l|}{ Intralaboratory variation } \\
\hline \multicolumn{3}{|l|}{ Intratechnician (LK) } \\
\hline $\mathrm{A}(\mathrm{n}=28)$ & $6.11(24.10)$ & $0.78^{\star}$ \\
\hline$B(n=33)$ & $5.57(22.31)$ & $0.77^{\star}$ \\
\hline \multicolumn{3}{|l|}{ Intertechnician (LK, FIB) } \\
\hline$A(n=33)$ & $-3.09(7.34)$ & $0.93 \dagger$ \\
\hline $\mathrm{B}(\mathrm{n}=38)$ & $-3.71(7.57)$ & $0.81 \dagger$ \\
\hline \multicolumn{3}{|l|}{ Interlaboratory variation } \\
\hline \multicolumn{3}{|l|}{ Intertechnician (LK, JYR) } \\
\hline $\mathrm{A}(\mathrm{n}=19)$ & $-1.00(16.43)$ & $0.82 \dagger$ \\
\hline \multicolumn{3}{|l|}{ Intertechnician (FIB, JYR) } \\
\hline A $(n=19)$ & $2.84(22.88)$ & $0.91 \dagger$ \\
\hline
\end{tabular}

A, biopsies not including the five with heterogeneous iron distribution; $\mathrm{B}$, biopsies with and without stainable iron.

$\Delta$, difference between means (expressed as $\mu \mathrm{mol} / \mathrm{g}$ dry weight). ${ }^{{ }} \kappa$ for four classes of iron concentration $(0-10 ; 10-20 ; 20-50$; $>50 \mu \mathrm{mol} / \mathrm{g}$ dry weight).

$+\kappa$ for three classes of iron concentration $(0-20 ; 20-50 ;>50$ $\mu \mathrm{mol} / \mathrm{g}$ dry weight).
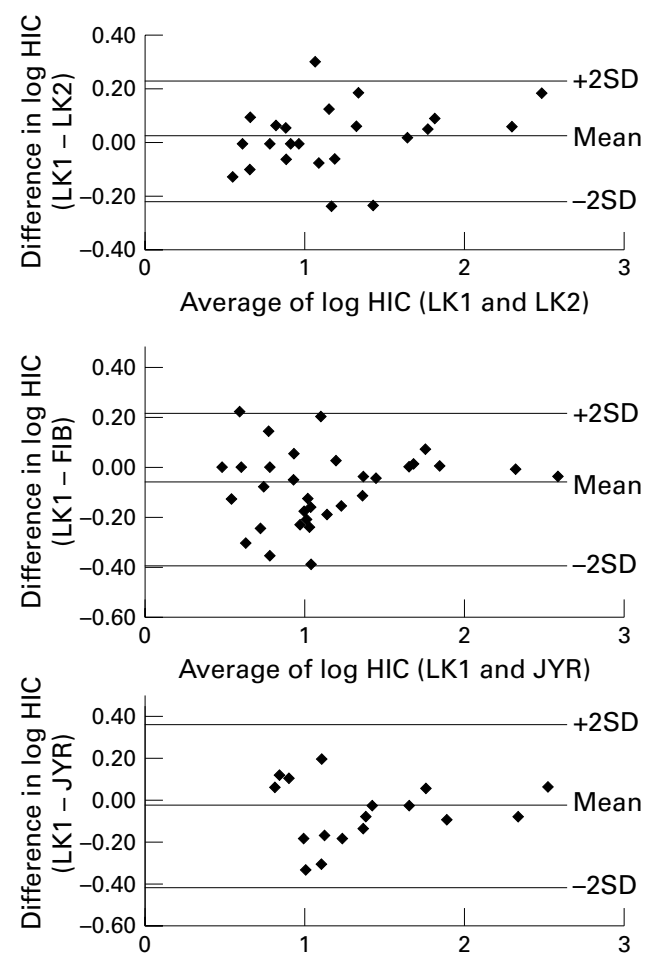

Average of log HIC (LK1 and JYR)

Figure 1 Variability of hepatic iron concentration (HIC) expressed as $\mu \mathrm{mol} / \mathrm{g}$ dw. Top: Intralaboratory, intraoperator: difference between LK1 and LK2 HIC measurement (log HIC) against the mean of the pair. Middle:

Intralaboratory, interoperator: difference between LK1 and FIB HIC measurement (log HIC) against the mean of the pair. Bottom: Interlaboratory, interoperator: difference between LK1 and FYR HIC measurement (log HIC) against the mean of the pair. 


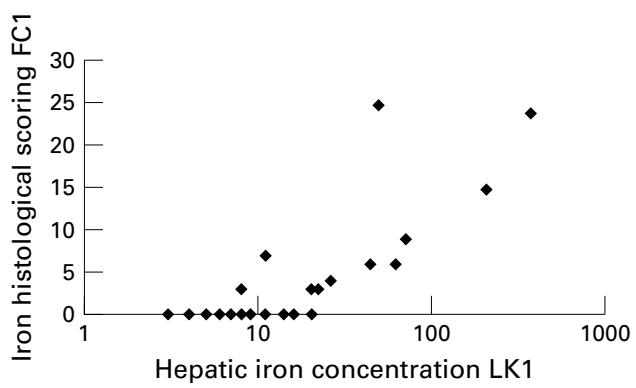

Figure 2 Comparison between iron histological scoring (FC1 reading) and LK1 HIC measurement (log HIC).

\section{Discussion}

The direct measurement of hepatic iron overload is usually based on two complementary methods, chemical iron concentration determination and stainable liver iron scoring. The chemical assay is considered to be the reference method for quantifying the total hepatic iron content. ${ }^{2021}$

Iron concentration measurements in deparaffinised liver tissue and fresh tissue have been shown to be concordant. ${ }^{22}{ }^{23}$ Hepatic iron content measurement is not influenced by haemoglobin iron, which forms only a minor fraction provided the specimen is properly washed. ${ }^{2024}$ Nevertheless, it was estimated to be about 2 $\mu \mathrm{mol} / \mathrm{g} \mathrm{dw}$ by Van Eijk et al, ${ }^{24}$ and this might be significant where small quantities of hepatic iron are being measured. The storage of liver biopsies in saline or formalin could also influence the results of iron concentration measurements. ${ }^{2324}$ It has been reported that the immersion of liver tissue for one hour in isotonic saline results in up to $50 \%$ loss of iron; $4 \%$ formaldehyde immersion is preferred since it causes much less iron loss. ${ }^{23} 24$

To our knowledge, the precision of colorimetric methods and the variability of chemical and histological methods have never been exhaustively assessed where hepatic iron content is low. With regard to the precision of the colorimetric assay, we found a within-day and day to day CV of $11 \%$ and $19.5 \%$, respectively. Our within-day $\mathrm{CV}$ was similar to that reported by Kreeftenberg and colleagues (CV 9.8\%) with another colorimetric technique. ${ }^{21}{ }^{24}$ Within-day CV $(\sim 6 \%)$ has been shown to be lower using atomic absorption spectrophotometry than in the colorimetric assay but the liver samples were larger. ${ }^{17} 212325$ The day to day CV of colorimetric methods has never previously been reported. For 21 biopsies from group A with iron concentration $\leqslant 20$ $\mu \mathrm{mol} / \mathrm{g} \mathrm{dw}$, the $\mathrm{CV}$ of the iron concentration measurement determined for two separate samples from the same biopsy was $14.7 \%$. Barry and Sherlock ${ }^{17}$ reported a CV of $8.6 \%$, equivalent to a standard deviation of $1.2 \mu \mathrm{mol} / \mathrm{g} \mathrm{dw}$, but only eight patients were studied and the dry weight liver samples were heavier (mean $9.4 \mathrm{mg} \mathrm{dw}$ ).

It is particularly important to assess the intralaboratory and interlaboratory variability of hepatic iron concentration measurements for low liver iron levels. We found only slight variation in interlaboratory and, in the same laboratory, intraoperator and interoperator results. With respect to the intralaboratory variation, the inclusion of five liver biopsies with uneven iron distribution in group A did not modify the results of the statistical analysis.

Iron concentration variability can occur between samples from the same liver in cases of uneven iron distribution, particularly when there is an increase in fibrous tissue which contains little or no iron. ${ }^{25}{ }^{26}$ Histological analysis is therefore essential to explain such variability in iron concentration measurement of duplicate samples.

The histological iron scoring system of Deugnier et al was validated in genetic haemochromatosis but not for low iron content. ${ }^{16}$ In our population, all the patients except two (36 of $38 ; 95 \%$ ) had a hepatic iron concentration below $70 \mu \mathrm{mol} / \mathrm{g} \mathrm{dw}$. The scoring system was modified in our study to take account of the uneven iron distribution by applying a heterogeneity coefficient to the total iron score. For the first time, an extensive statistical analysis of intraobserver and interobserver variation in a histological iron scoring system was undertaken. Only one previous study showed small intraobserver and interobserver variation, but that study was limited to the use of the non-parametric Spearman test on cases of hepatic iron overload. ${ }^{16}$ Using the $\kappa$ test, we showed that the strength of interobserver and intraobserver agreement was almost perfect, or at least substantial, for all items except for the sinusoidal score, where the strength of interobserver agreement was only moderate.

A significant correlation between iron concentration and histological scoring has been reported, though not for low and high iron concentrations. This may be explained by the varying iron distribution between ferritin and haemosiderin at different levels of iron content. ${ }^{12} 1520$ For low hepatic iron loads, we found good concordance between iron concentration and histological score in the present study. This may be explained by our use of the new histological scoring system. ${ }^{16}$ When we observed no stainable iron, the hepatic iron concentration did not exceed $20 \mu \mathrm{mol} / \mathrm{g} \mathrm{dw}$.

The advantage of histological scoring is that it provides information on iron distribution and on the possible redistribution of iron in the different hepatic sectors. This might be relevant in the study of some liver diseases. ${ }^{11} 1527$ Its disadvantage is that it is less accurate than the chemical determination, particularly in cases of low iron load (linked mainly to unstainable ferritin). The advantage of the chemical assay is that it allows the quantification of all forms of iron, but it is unsatisfactory in cases of uneven iron distribution. It is therefore of the greatest importance that these two complementary methods are combined, especially in cases of low iron concentration.

\section{CONCLUSIONS}

Our study shows that the combination of colorimetric measurement and histological scoring is an accurate and reliable way of determining low hepatic iron concentrations in paraffin embedded tissue. These two methods should be used to study the low hepatic iron levels found in various liver diseases other than genetic 
haemochromatosis ${ }^{128}$ and in clinical research on cofactors involved in liver fibrogenesis. Supported by a grant from the Association pour la Recherche
sur le Cancer et URA CNRS 1484. We are grateful to Danièle sur le Cancer et URA CNRS 1484. We are grateful to Danièle
Le Quilleuc and Jean-Yves Robert for their excellent technical assistance.

1 Farinati F, Cardin R, De Maria N, et al. Zinc, iron and peroxidation in liver tissue. Cumulative effects of alcohol conoxidation in liver tissue. Cumulative effects of alcohol consumption and virus-mediated damaged.
report. Biol Trace Elem Res 1995;47:193-9.

2 Paradis V, Mathurin P, Kollinger M, et al. In situ detection of lipid peroxidation in chronic hepatitis C: correlation with pathological features. F Clin Pathol 1997;50:401-6

3 Britton RS, Bacon BR. Role of free radicals in liver diseases and hepatic fibrosis. Hepatogastroenterology 1994;41:343-8.

4 Van Thiel DH, Friedlander L, Fagiuoli S, et al. Response to interferon alpha therapy is influenced by the iron content of the liver. F Hepatol 1994;20:410-15.

5 Olynyk JK, Rajender Reddy K, et al. Hepatic iron concentration as a predictor of response to interferon alpha therapy in chronic hepatitis C. Gastroenterology 1995;108:1104-9.

6 Clemente MG, Congia M, Lai ME, et al. Effect of iron overload on the response to recombinant interferon-alpha treatment in transfusion-dependent patients with thalassemia major and chronic hepatitis C. F Pediatr 1994;125:123-8.

7 Bonkovsky HL, Banner BF, Rothman AL. Iron and chronic viral hepatitis. Hepatology 1997;25:760-7.

8 Bader T, Caroll N, Adcock D. Relationship of hepatic iron Bader T, Caroll N, Adcock D. Relationship of hepatic iron
levels and sustained response to alpha-interferon [ablevels and sustained response

9 Arber N, Moshkowitz M, Konikoff F, et al. Elevated serum iron predicts a poor response to interferon treatment in patients with chronic HCV infection. Dig Dis Sci 1995;40 2431-3.

10 Barton AL, Banner BF, Cable EE, et al. Distribution of iron in the liver predicts the response of chronic hepatitis $C$ infection to interferon therapy. Am F Clin Pathol 1995;103: 419-24.

11 Boucher E, Bourienne A, Adams P, et al. Liver iron concentration and distribution in chronic hepatitis $C$ before and after interferon treatment. Gut 1997;41:115-20.

12 Brissot P, Bourel M, Herry D, et al. Assessment of liver iron content in 271 patients: a reevaluation of direct and content in 271 patients: a reevaluation of direct

13 Deugnier Y, Loréal O, Turlin B, et al. Liver pathology in genetic hemochromatosis: a review of 135 homozygous cases and their bioclinical correlations. Gastroenterology $1992 ; 102 \cdot 2050-9$

14 Bacon BR, Tavill AS. Role of the liver in normal iron metabolism. Semin Liver Dis 1984;4:181-92.

15 Van Deursen C, De Metz M, Koudstaal J, et al. Accumulation of iron and iron compounds in liver tissue. A comparative study of histological and chemical estimation of liver iron. $\mathcal{7}$ Clin Chem Clin Biochem 1988;26:446-50.

16 Deugnier YM, Turlin B, Powell LW, et al. Differentiation between heterozygotes and homozygotes in genetic hemobetween heterozygotes and homozygotes in genetic hemostudy of 192 cases. Hepatology 1993;17:30-4.

17 Barry M, Sherlock S. Measurement of liver iron concentration in needle biopsy specimens. Lancet 1971;i:100-3.

18 Bland JM, Altman DG. Statistical methods for assessing agreement between two methods of clinical measurement. Lancet $1986 ; \mathrm{i}: 307-10$

19 Landis RJ, Koch GG. The measurement of observer agreement for categorical data. Biometrics 1977;33:159-64.

20 Barry M. Liver iron concentration, stainable iron, and total body storage iron. Gut 1974;15:411-15.

21 Kreeftenberg HG, Koopman BJ, Huizenga JR, et al. Measurement of iron in liver biopsies - a comparison of three analytical methods. Clin Chim Acta 1984;144:255-62.

22 Van Deursen C, De Metz M, Koudstaal J, et al. Measurement of liver iron content in paraffin-embedded biopsies. F Clin Chem Clin Biochem 1988;26:689-91.

23 Olynyck JK, O'Neill R, Britton RS, et al. Determination of hepatic iron concentration in fresh and paraffin-embedded tissue: diagnostic implication. Gastroenterology 1994;106: 674-7.

24 Van Eijk HG, Wiltink WF, Bos G, et al. Measurement of the iron content in human liver specimens. Clin Chim Acta 1974;50:275-80.

25 Villeneuve JP, Bilodeau M, Lepage R, et al. Variability in hepatic iron concentration measurement from needlebiopsy specimens. 7 Hepatol 1996;25:172-7.

26 Deugnier Y, Turlin B, Le Quilleuc D, et al. A reappraisal of hepatic siderosis in patients with end-stage cirrhosis: practical implications for the diagnosis of hemochromatosis. Am F Surg Pathol 1997;21:669-75.

27 Milman N, Graudal J, Hegnhoj J, et al. Relationships among serum iron status markers, chemical and histochemical liver iron content in 117 patients with alcoholic and non-alcoholic hepatic disease. Hepatogastroenterology 1994;41:20-4.

28 Turlin B, Juguet F, Moirand R, et al. Increased liver iron stores in patients with hepatocellular carcinoma developed on noncirrhotic liver. Hepatology 1995;22:446-50. 